\title{
Literacy lessons learnt from parents after attending a seven-week Home-School Partnership Programme
}

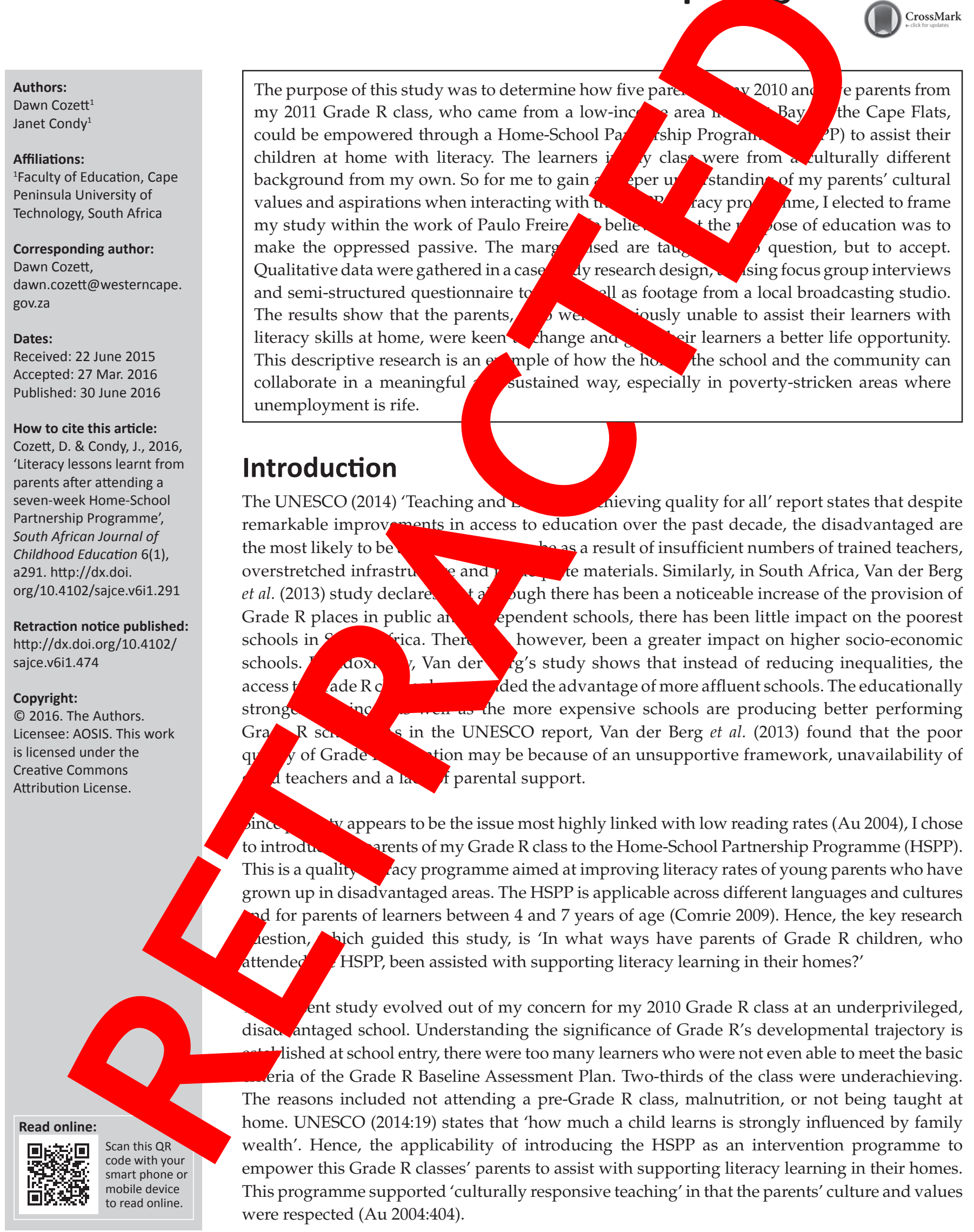




\section{Theoretical framework}

This research project was conducted in a poverty-stricken environment. Freire (1970) believes that 'classes' have different ideological cultural values and aspirations. I came from a middle-class suburb some distance from the school where I taught, so I was unfamiliar with the community where my learners lived. In essence, I was from one class and the learners were from another (Au 2004). So for me to gain a deeper understanding of my parents' cultural values and aspirations when interacting with the HSPP literacy programme, I elected to frame my study within the work of Paulo Freire (Freire 1970). His work explores how it is to be human and what it means to connect and live with the 'other'.

For Freire, class remains an important factor in his understanding of oppression. He believed the purpose of education was to make the oppressed passive. The oppressed are taught not to question, but to accept. This minimises the oppressor's creative power. Freire (1996) suggests that education becomes oppressed when it is prescribed:

Every prescription represents the imposition of one individual choice upon another, transforming the consciousness of $t$ ] person prescribed to, into that which conforms to the prescriber consciousness. (p. 29)

Because Freire considers literacy to be much more than just the ability to read, and regards literacy as the ab man 'the word and the world', literacy is a social term to term 'social literacy' enables parents to recognise thei teachers of a broader kind of literacy. Shor (1999) furt this discussion by suggesting that literacy is a social act which uses language inside a larger cul agrees with Freire (1996:57) that studen objects of interrogation rather than through a culture of pedagogical encourage questioning. Critical 'learning to read and write as $\mathrm{p}$ ? conscious of one's experieng within specific power relatio as historically con cted coulo d texts as shly re (2011:5

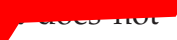
cerstood as states that Freiran pedago for the opportunity to read, write and lea by engas a culture of questioning, which do gnds more than competent rote learners.

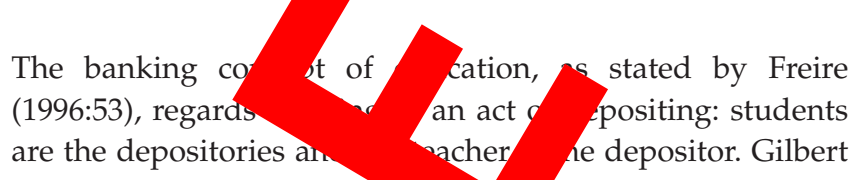
are the depositories al nacher depositor. Gilbert (2012:119) oncept as funnelling knowledg ' $s$ ' heads. ' Danking concept' (Freire 1996:55 guises efforts of the humanist to turn women and $\mathrm{m}$ maton conformity prevents self-direc $\mathrm{g}$, critical thinking and autonomy in action. It enco disconnected knowledge. In terms of the 'banking systern learning, the narrative educator talks and the learner liswns. The learner listens, memorises and repeats without any real insight or understanding of what they learnt. The learner is treated as a 'tabula rasa' or an empty vessel that needs to be filled. The educator chooses the content and context of the study and learners adapt to it. Learners are passive and accept the world as oppressors portrayed to them. The learner is in the world, but not with the world. The learner is not making meaning of the knowledge that he is $\mathrm{fi}^{\mathrm{y}}$ king' serves the interest of the oppressor (ed or), who not care to have the world revealed or sformed. This oach stifles growth and development 996:58).

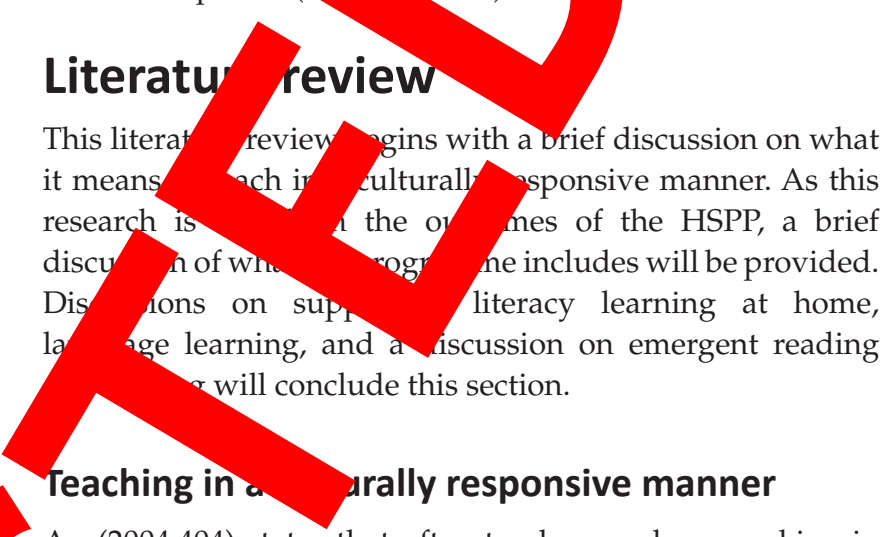

$\mathrm{Au}$ (2004:404) states that often teachers end up working in classrooms with students from culturally different backgroun from their own. These teachers want to teach values, cu es and behaviours that reflect those of their learners purpose of culturally responsive teaching is to ademic achievement, not just to build self-esteem
or cuntural identity, although these may be positive outcomes of this approach. It is important for learners from diverse

frounds to acquire academic skills, as they need to be able to compete in the larger society. People are judged on how well they can speak, read and write in English. In culturally relevant teaching, teachers are mindful of teaching students in a manner that respects their values and home cultures (Au 2004).

In this study, the parents of the Grade $\mathrm{R}$ learners valued the principal of Ubuntu, which 'recognises the African philosophy of humanism, linking the individual to the collective ... It is a way of life, ways of treating others and ways of behaving' (Sotuku \& Duku 2014:29). This HSPP valued these principles by nurturing relationships between parents and learners, parents and teachers and parents and the school. The programme specifically set out to develop the parent's self-esteem, self-confidence, as well as thinking and reasoning skills. They were motivated to create caring and reliable relationships with their children (O'Carroll 2014).

\section{The Home-School Partnership Programme}

O'Carroll (2014) director of WordWorks, states that the HSPP is a volunteer programme including parents, grandparents and caregivers to support learning in the home environment. The programme (Appendix 1) is conducted in high-poverty areas, where high levels of unemployment, drug abuse and gang violence are prevalent. Freire (1996) suggested that in these oppressive environments, learners are taught not to question, but to merely accept. Rote learning is encouraged where the educator talks and the learners listen and repeat without any real insight. 
However, the HSPP strives to achieve three outcomes: it fosters a culture of learning among families, to assist parents of young children with after-hours learning activities, and it nurtures constructive relationships between schools and families. The seven-week, user-friendly and fun course aims to equip participants with critical literacy skills, practical ideas and builds confidence necessary to support their children's learning at home. Participants are shown skills of how to: talk with babies and children, share stories and books, sing songs and play games with sounds, facilitate pretend play, point out print, provide opportunities for drawing and support early writing in English, Afrikaans, isiZulu and isiXhosa ( $\mathrm{O}^{\prime}$ Carroll n.d.).

\section{Supporting literacy learning at home}

Parental relationships that support literacy in the home environment form the necessary grounding for early childhood development (ECD). In many instances, parents and caregivers are not aware of the impact that these literacy activities have on their children's learning. The role of the family and the family environment itself has an effect on young children's emergent literacy development. Caregivers and teachers, together with families, help to create a basis for emergent literacy by providing literacy-related activities. For many years in South Africa, as Hickman and O'Carroll (2013) state, there has been a misconception that learning to read and write begins when children start formal learr The brain of an infant is impressionable; it is able to abs learn different skills, including language learning durir early years. Zeece and Wallace (2009) emphasise that liter development starts at birth. Swick (2008) accentuates the importar of h quality
parent-child relationships. Through of stent a)
interactions with their parents, childrein goodness. This forms the basis children can train each other interacting with the environmer form a bond with their chil

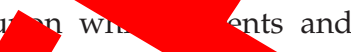
etter relaı. and arents therefore in to construct a sense of security and love. This is thim influencing children's growth and lea g. Mui am arson (2008) continue this argument ftating that home families are influential sites for acy learning. Mui and Anderson (2008:240) further stat at reading and writing are central in children's daily li In $\mathrm{n}$ instan'ses, parents and caregivers are not a impac at these literacy activities have on their $\mathrm{c}$

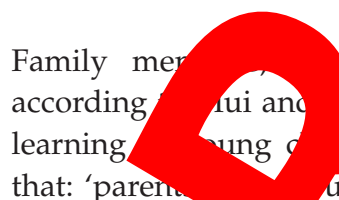

$r$ than ta is and mothers, as hderson (2008) can also support the ne. Comrie (2009) states araged to involve older brothers and sisters or other tam mbers in reading and telling stories to young children. teraction supports the older siblings' reading and sense of responsibility. Mui and Anderson (2008) state that, at times, literacy learning occurs in the context of playing 'school'. Older children feel it their responsibility to help prepare their younger siblings for school entry or the next grade. Immediate family members and extended families need to support younger children to develop basic literacy skills. Mui and Anderson (2008) state 'that the value of older children assisting their younger siblings is that they bene plain (2008):

The older children le arious ways sent information to the younger chil teaching the mportant literacy knowledge while a ame time $y$ enhancing and reinforcing thei wow lite

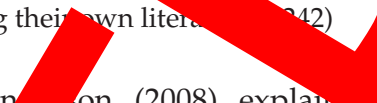

Mui and An on (2008) explaim rat because of the increasing ry nat gra arents and significant other adults play in the childre tildren not always being raised by heir b. 1 paren important role of such person ould be aci The guidance and support that nts and/or care offer to young children is con critical. Zeece and Wallace (2009) agree that y so literacy and language abilities depend on port prov

Jot all parents are comfortable and confident enough to assist their children in an overt role. Therefore, suitable support promammes should be made available so that parents do $n$ eel pressured to perform in the company of thers. Ott 008) and de Coulon, Meschi and Vignoles ompelling arguments about the harmful effects than r w rits with poor literacy skills have on their young children's literacy development. It may not only have an on their children's schooling but also affect mproyment and family income. Other factors mentioned by Otto (2008) are that parents may face unemployment, having to work away from home and/or hold an unstable job with low wages. The amount of time spent together could be affected by these factors. In a South African context, where many Grade $\mathrm{R}$ learners come from low-income families, it is important to recognise the factors which contribute and prevent successful literacy achievement.

According to Grisham-Brown (2008), children's growth and the way they learn are influenced by those who care for, and educate, them. To give children, from socio-disadvantaged backgrounds, a better chance of learning to read and write successfully, as stated by O'Carroll (in Comrie 2009), foundations for learning must be laid before the start of formal schooling. Teaching children to read and write should therefore be an on-going process. Imitation is a powerful form of social and cognitive education. Children's peers, older children and senior members of the community, such as parents or teachers, can all use this instinct to initiate a way of leading or directing children. The HSPP promotes participatory democracy in communities, which, according to Amasa and Thokazani (2011:132), 'increases individual freedom by enabling learners to be their own master and increases the feeling that learners belong to their own community'.

\section{Language learning}

At the time data were collected for this research project, the Revised National Curriculum Statement (2002) (RNCS) was 
being used. Hence, I will refer to this document. In the Grade R curriculum (RNCS 2002:13), oral language is the foundation and the primary means of communication. Language inspires imagination and creativity; it eventually provides and promotes many of the goals of science, technology and environmental education. It develops the critical tools necessary for becoming responsible citizens. The RNCS (2002:13) requires that learners entering Grade R and Grade 1 to have a high proficiency in their home language. These learners should have developed their home language through a variety of interactions with others in the context of care, nurture and play. The focus should be on listening for information and enjoyment, communicating confidently and effectively in a wide range of situations, reading picture books and learning songs and rhymes, drawing pictures and being able to use vocabulary appropriately. The learners will be able to understand concepts such as identity, number, size and colour (RNCS 2002:16).

\section{Emergent reading and writing}

Zeece and Wallace (2009:36) state that literacy developmen begins at birth and is highly connected with success at schoo Girard et al. (2013) posit that emergent literacy is the skill an knowledge that precede formal reading. Emergent literacy supports the development of decoding and reading comprehension. Children interact with their environment by means of their five senses from birth. Their ser motor experiences of touch, smell, taste, sight and hear them to explore their environment.

When young children become aware of environmental p such as product labels, clothing, igns ano advertisements, they realise that Comrie (2009:9) describes this experi a big 'jump' from noticing real concr objects being represented by word" as described by Neumann, Hor hd Neumà. can be asked to trace letters in wo with their fingers the word is being sounded out tein (2011) offers insight into early word-play; song d d for example, set the stage for teaching pho gical awa. Learning the concept that letters co spond to sounds to their names provides the dation for reading. Chohan (2011) explains that pre-w g skillarare best learned when children are allowed to of ise an onvey thair thoughts. Cabel, Tortorelli and Go expound at young children who are exposed to ring ey ences are provided

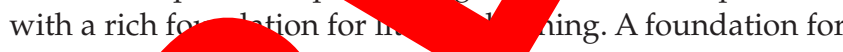
literacy le des an un tanding of writing on a page freft to ht, drawings and sound awareness. Childr an lend information about their una of print and sound. The writing is often no more than text in their environ. d the scribbles become horizontal and move from left to rigut on a page.

Furthermore, Cabel et al. (2013) state that children's drawings are their writing and that this process helps young children to figure out how writing works in an informal manner. Children often represent salient sounds or the sounds that are the most prominent because of the way they feel in the child's mouth. When a child bas the ability to identify salient sounds in words and to a letter, it indicates that that child has b to soun the words she wrote phonetically, for e ple, by labelli picture of a tiger with a ' $\mathrm{T}$ '.

This section gan by dis are's theory of the oppressed what it means to e different ideological cultural $y$ as and pirations. Throughout the literature review, a given $t$ eracy development in the home disc what it ans to teach in a culturally resp ve manner, is of the HSPP were described, the portance of suppo literacy learning at home, how iact linked to the RNCS policy document and finally fie. aion on emergent reading and writing skills.

Methodol

A case study methodology was used to conduct an in-depth investigation into what ways parents of my Grade R learners were emp ered by attending a seven-week literacy interventi rogramme. Case studies, as stated by Cohen, Morrison (2008:253) can 'establish cause and observe effects in real contexts, recognising that ontext is a powerful determinant of both causes and effects'. tudy reports on the 'complex dynamic and unfolding interactions' of the literacy gains.

I opted for a convenient sample of parents, as this group was easily accessible (Cohen et al. 2008). It was convenient for me to approach the Grade R parents as I saw them in the morning when they brought their Grade R children to school and in the afternoon when they collected their children after school.

The school selected for this study is located in a low-income area in Hout Bay near to a small fishing village and surrounded by two mountains. The parents speak predominantly Afrikaans and English. Many parents from this community would insist that their children be taught in English even though their home language is Afrikaans. The school falls within 'quintile one' group of public schools, which means it is 'no-fees' school. The no-fee policy exempts certain schools from charging fees, based on poverty levels of the area they serve (James 2001). However, at this school, the Grade R learners pay an annual fee of R350.00 and this allows the learners to be fed daily by the Provincial Feeding Scheme. This is a Department of Basic Education (DoBE) initiative that supports the learning programme at the school and in the Western Cape.

The sample consisted of five parents who had children in my Grade R class in 2010. During February and March 2010, these five parents attended a seven-week HSPP, which I conducted in English. The following year, during May 2011, I had to find another five parents to be interviewed. 
These parents attended the same HSPP in 2010 but were interviewed to add more depth to the findings. The first sample group did not display sufficient responses to the required study and it therefore lacked depth (Creswell 2009).

I asked open-ended questions in a series of focus group interviews, which were crucial to this research programme (Creswell 2009). In 2010, I conducted interviews after each week of the seven-week HSPP. During February and March 2011, e.tv videoed the HSPP over a period of four weeks, and I have transcribed and reproduced a video clip from that filming. On the final evening of the HSPP, I invited the parents to complete a semi-structured questionnaire.

During the time of inductive data analysis, I used eight different coloured pens to code the text of the interviews, semi-structured questionnaires and the video recording. The codes were Personal Development was coded in red, ECD was coded green, Building collegiality in the community was coded yellow, Developing skills was coded purple, Time management was coded silver, Strengthening relationships was coded blue, Positive self-esteem was coded orange, and finally Future hope was coded turquoise. When categorising these classifications, some codes were discarded (Henning, Van Rensburg \& Smit 2007). Eventually, the codes were categorised into five more frequently occurring classifications according to the theoretical framework and the literature review.

Triangulation, as explained by Cohen et al. (2008), the strengthening of reliability in a study, when differ methods of data collection produce substantially the same results. To ensure triangulation, I compare of the interviews, questionnaires and vid generated considerably similar finding data analysis above. The more the data ecord which displayed similarity with each ot the mi fident I became and this strengthened my earch study.

Participation was voluntary. HSPP were assured of (Henning et al. 2007). I hav when discussing the $r$ conduct this research the principal of my lo whe study conducted. In addition to this, I Way permiss to use the video clip, which was aired on var the South African Findir

In an attem $r$ the research question 'In what ways have parents of children, who attended the HSPP, been assisted with ing literacy learning in their homes?', five classification were identified on a regular and consistent basis. They include: parents' personal development; understanding of ECD; building collegiality in the community; developing skills to assist children with initial literacy at home; and parents learning to manage their time. In the examples of the findings, the exact words that the parents used are shown. For the sake of authenticity, the grammatical structure of their sentences has not been changed.

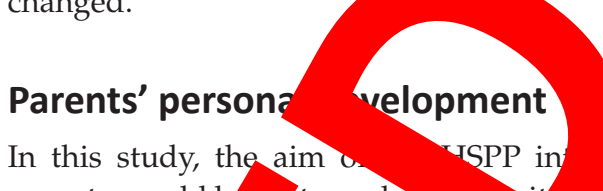

In this study, the aim o- USPP in ention was that parents would b to under it teracy principles. The participar vere able to reco the important role they play in your sildren's development. They also

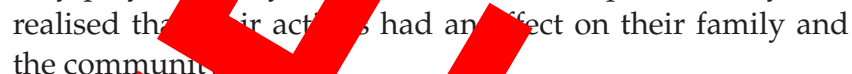
the commun

The H had brough together in that they were read together: older sibung wanted to be part of the re Comrie (2009) encouraged the involvement of brou sisters in reading and telling stories to anger sibling ars had taken on the responsibility of ssisting their child at home with story-telling and going to the library. Some of the interviewees had this to say:

'I am no longer the same. At first I would say 'not now' but now I want to d ings.' (FM)

'It brings family together.' (LB)

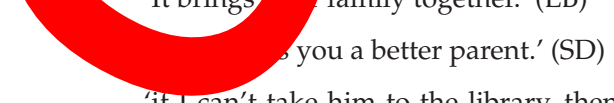

'if I can't take him to the library, then my husband takes him.' (JA)

ast year my wife was telling stories, but then she say no and you know it's not only for your wife to tell the stories so I took that part from my wife. And so now I'm the one who tell the stories to the child and she enjoy the stories.' (LB)

'... having fun with my children ... You see, it's more fun and exciting and uhh because books in the shops are very expensive, so it's best to make books at home ...' (LW)

'I am proud to be a mother ...' (JA)

Participants indicated what they enjoyed doing during the programme and how this improved their relationships with their children. Most of the participants indicated that they needed programmes such as the HSPP to assist their children before they went to school. This helped build a better relationship with their child. They mentioned that the programme was empowering and interesting. One response was as follows:

'The connection that I used to have with my child was not so good at first but now we understand each other.'

It seemed that parents felt good about the change that was happening in their families. Parents realised that the programme gave them ideas to assist their children with learning in a fun way. While many parents felt that they were being equipped to assist their young children, some indicated that they needed a programme to focus on helping older children and children who were experiencing difficulties with their school work. LB had the following to say:

'I think, how many years I waste because I just send my eldest daughter to school and uhh I come back and I just leave her by the 
teacher. But now with this education programme has made a big difference in my life. I know that I must work with my child every day and I mustn't stop working with my child because it's an ongoing thing. You know, if I can do this programme every year ...'

The parents discovered that they could play an important role not only in their children's development but also with their own personal development. It seemed that they realised how much they needed an intervention programme such as the HSPP to assist them to make a difference in their own lives as well as in the lives of their young children.

\section{Understanding of early childhood development}

Piaget (in Donald, Lazarus \& Lolwana 2007:53) believes that ECD's focus is on children learning through play, exploring their environment and 'trying things out'. It is at this stage of development that the 'power of play' develops a natural curiosity in children (RNCS 2002). It is thought that children learn more efficiently and gain more knowledge when given the opportunity for play-based activities such as dramatic play, art and social games. This theory is based on children' natural curiosity and tendencies to 'make believe'.

One of the interview questions was: 'Are you still playin language games with your child?' Two parents responded:

'during bath time and ... while he is dressing himself, there is a lot of activity ... like when he's pronouncing words wrong, we'll teach him how to pronounce it right in actually a pla we are still teaching him ...' (JA)

'I like to play language games with my child... I can improvement ... last year she was struggling a bit with English and uhh you can see through the ga

Two parents indicated in the semi-s improved since they were doing th red qu home. Some could see the value how it brought about calmness
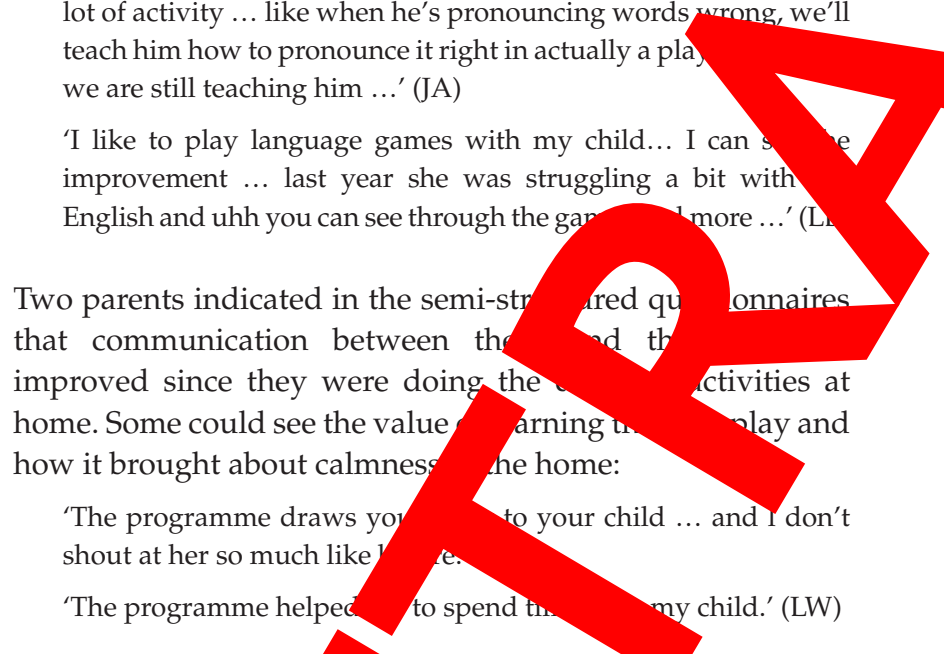

One mother mention nat she realised she should not rush or put pressure on child. She came to know that it will take time for him anders and gmsp certain letters of the alphabet:

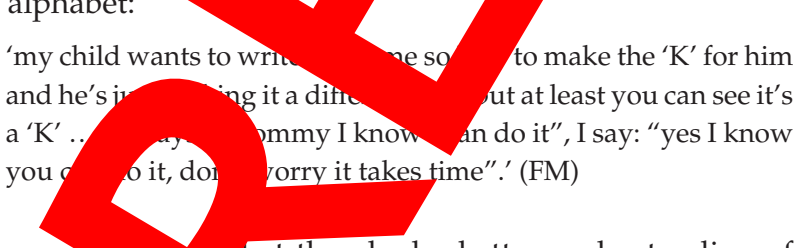

Many par hat they had a better understanding of how young ch learnt. It made them more confident about assisting then n a home. Some participants felt empowered and underrood early childhood education. Others were hopeful about the future for the first time. Parents had a more optimistic outlook for their children's educational future.

\section{Building collegiality in the community}

During the HSPP, we encouraged the parents to think about ways they taught their young children and what effect it had on their own developm most significant response was that 'the parents reacm reloped trust amongst each other'. This uraged goo tionships between myself and the $\mathrm{p}$ ants. We disc red that we could learn from one anot

There were participants in ntioned in the semistructure $g$ tionnai that they enyoyed being part of the group. Q artici wrote serning the importance of sharing the mis that you have for your for our kids,

he other wrote about being surrounded by many people and the s and learning in a short space of time:

I enjoyed being surrounded by lots of people and the teachers and things 1 learned in a short period of time ...

Sharing $d y \quad g$ the sessions gave the parents a chance to discuss ar upport each other. During the interviews, the re asked whether they shared the information gained over the seven weeks with other participants:

yes, with all my friends and my neighbours coming to me.' (A)

'I can't stop telling them what a privilege it is to be in an education programme like this.' (LB)

'I will say to the parents it's nice to do this and then it opens up your mind ...' (JW)

One parent shared during an interview session that, prior to the HSPP, she would normally just walk past people. Ever since the HSPP, she now greeted and had conversations with people that she met at the HSPP:

' we normally didn't greet, we just past each other... but now it's exciting, we say "hi". We communicate about what happened in the class and outside ...' (FL)

O'Carroll (in Comrie 2007) states that the HSPP promotes informal learning and is applicable across languages and cultures. In the evaluation forms, some parents made recommendations that, in future, the programme should be introduced to parents of other cultures and the wider community. Some referred to the informal settlement that is situated near the school. Four participants mentioned:

'... involve the community of IY.' (Imizamo Yethu - an informal settlement in the Hout Bay area)

Eight participants felt strongly and stated:

'... open it to the broader community ...'

These parents felt that there is hope for those who had not yet had a chance to be introduced to the HSSP. 
Two parents recommended that, through the HSPP, South African youth can benefit:

\section{'... SA youth rainbow nation'}

'... build a strong nation ...'

One of the interviewees mentioned that more parents should be attending programmes such as the HSPP:

'... if more parents can attend these classes, it will make a big difference ...' (LB)

Parents exhibited enthusiasm to collaborate as a community; they gradually but observably learnt to encourage others to participate in the HSPP programme. They were eager to share their experiences with others in the community and extend this programme to the local informal settlement. This supports Mui and Anderson's (2008) idea that homes and families are influential sites for literacy learning. These parents developed ambitions beyond their own private concerns and began to widen the scope of their concern to the altruistic desire for others to succeed as well; they wanted to see children of other parents in the local community succeed. This broadening of interest was demonstrable from the findings and one of the most significant results of the intervention as a whole.

\section{Developing skills to assist children with initial literacy at home}

The banking concept, according to Freire (1996:54) 'm creativity'. He refers to the students accepting the pa role imposed on them and that they do not develop as crit conscious beings. In this study, the HSPP allowed the parent an opportunity to ask critical questions started asking advice on how to teach literacy children at home. Reading stories to th a picture or spending time interactir taught parents by practice what to

Many of the parents, had been did not know how to implem because they themselves hag (Freire 1996). Many of them with excitement, encour ven ad to as children ously marginaliso dd hildren ked the sk olling a story ng drawing or ing time interacting with their ren. These parents nerther knew how to spend time w heir children nor how to turn that time into an inform arning erience (Au 2004). During an interview, one s becam cited when she explained the manner she s reading to her children and thenstions thiom:

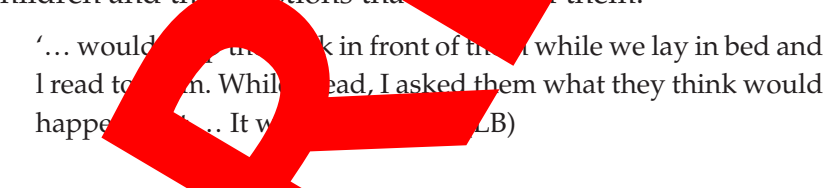

As the progran barents began to experience a sense on yement when they made little books. Once they folded nd cut their pages, they were excited to make more books at home with their children. This activity was followed by a discussion on the importance of making your own books and what children could learn from this experience. At the end of this session, participants were given homework which was to make their own books. The following week they had to show their books to the whole group. This increased their conse of independence and usefulness (Cabel et al. rents mentioned that making your own boo'

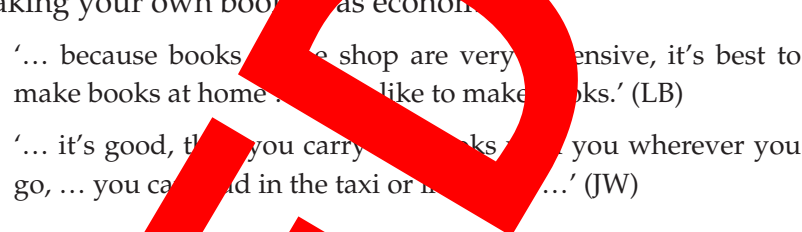
The makin books ame a fy activity for parents and
their childre mention in the a questionnaire that she strugg with the cut olding of the little books. It seen hat it turned out tho his became a fun activity:

rt is when you struggle to cut and to fold it [the page] nd then a laugh, that's the best part.' (MS)

nstead of watching evision aimlessly or being exposed to violent acts in the community, parents and children were having fun through learning language (Au 2004; Freire 1996). They were al to laugh together and laugh at themselves. Parents bece hopeful since they became aware of the mortan listening to their children. They had been all of making their own books and realised why language development was significant in their children's mment from one parent who seemed hopeful and eager to exercise what he had learned through the programme.

'... you showed us how to make puzzles and hum that makes me excited ...' (LB)

It seemed that once the parents understood the importance of language learning and what their children were able to learn through having books and puzzles available, they were more than eager to further their skills in these areas. It became evident that this project disrupted Freire's (1996:54) notion of 'minimising creativity'.

\section{Parents learning to manage their time}

Throughout the seven-week HSPP, the parents were encouraged to adjust their schedules in order to make time for their children. The situation of family life changes continuously. At first, most of the parents did not seem to understand the importance of time management or of making time for this course. However, later in the programme, they began to see the significance of planning their time.

During the interviews, two of the parents indicated that they did not always have time to do what they were taught during the programme. One parent did, however, mention that she did 'Maths and that she read with her child':

\footnotetext{
'... now that 1 have the little one, I do not have much time to make little books.' (JW)

'... because there's not always time for that [playing language games], but we do the maths and the reading ...' (GB)
} 
One of the fathers, who was interviewed, stated he realised that he had to change the ways he spent his time at home. His role was to assist his wife with their child:

'Daddy's must be there to help his wife with the child. He mustn't just sit with the newspaper or in front of the TV [television]. Help the wife, help the child and so you can make a better life with your child.' (LB)

In two of the final semi-structured questionnaires, parents commented that one of the things that they enjoyed about the programme was how they spent time with their children. It seemed that the HSPP assisted parents to use their time more effectively (Au 2004). The two phrases that substantiate this point are:

$$
\begin{aligned}
& \text { '... how to help my child ... and spend time.' } \\
& \text { '... know [now], I'm spending more time with my kids ...' }
\end{aligned}
$$

Other parents, in their semi-structured questionnaires, mentioned their ideas of how they used their time to assist their children with learning language. Parents showed that they understood that there were different ways for their children to learn. They commented by writing the following statement

'... because my daughter is a slow leaner, I can help her a lot wi her schoolwork through play ...'

' to teach my children things that I never done, like routine ...'

'... the games, reading books and how to teach my children to read and write...'

'... by listening and hearing ...'

Many of the parents who attended the programme rea that they might have made a good choico-registering participate in the seven-week HSPP. The themselves to the seven weeks. This $\phi$ was beneficial to them and thei participants was a grandmother who cer time to rising

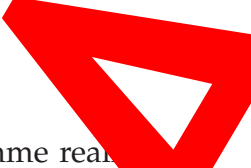
ommitted heir time attend the seven-week programn he mein in the e.tv interview that she did it for the ef her granu so that she could assist them at e. This woman reat d the important role that she $\mathrm{p}^{1} \quad$ grandparent and the difference that she could re tom grandchildren's future lives.

\section{Discussion}

The purpose of th adyw determine the efficacy of the HSPP and how pa. de R lear were empowered to assist their childreln we wit arning literacy. The HSPP is un strably a successful interventi for a critica uation in South African educatic gardin teracy (Au 2004). It is an attainable and realisti agram a in the South African Constitur every child has the right to be taught, to be literate. Thu project provides evidence that these parents were empo to assist their Grade R children with literacy learning in ve home environment.

The reality of re-structuring an entire educational organisation after the disruption and crippling after effects of Apartheid has proved far greater than expected (Freire 1996). The implementation of a fair and egalitarian educational option for all has been arduous and expensive. Inevitably, despite the best, often heroic, efforta of dedicated educators, many communities have no rectly or materially in accordance with the ns of the in nstitution (Au 2004). The DoBE envisag eprovision of ty education for all children in an edur training stem that respects and responds cectively learning needs of every child. The findi In this earch proiect indicate that the home, school an $y$ canno ork in isolation from each other par exper socio-economic hardship tant that today un al education includes adults as bildren (UNESCO 2014). A learning family refers to rents a home that is rich in learning resources by sing inexp or re-usable material. A learning street describes good of vocabulary, print-rich signs and notices. A learning community illustrates a community with neighbours sharing books and grandparents telling their stories to th hildren at school or at home. Forming this kind of partner increases children's self-esteem, motivation, academi als and independence so that they can achieve develop their full potential.

This study had certain limitations. Only parents of Grade R ers from one school were involved. The study only investigated the impact that the HSPP had on literacy learning. Nevertheless, it is possible that its findings may be generalised by analogy (naturalistic generalisation) to similar contexts. Future research plans include a broadening of our research base to include schools offering the HSPP in a variety of contexts.

A few recommendations are suggested. The DoBE continue to recognise the importance of the principles and practices of social and environmental justice and that they incorporate such principles and practices into curricular development. Schools can offer programmes, such as the HSSP, which empower and teach parents to become more aware of what they are able to offer their children and participate in informal literacy activities at home. Especially in Quintile 1 schools, it is recommended that school management bodies create opportunities to develop partnerships with their parents. The focus of these partnerships would be to extend the parents, and ultimately children's, early literacy and numeracy experiences in a creative and fun-filled manner. Schools, teachers and families could work collaboratively and be guided by the needs of the child to develop successful and resourceful learning experiences. As far as the research design is concerned and in terms of depth, it is recommended that the sample size be increased for a deeper understanding of the process. In preparation for interviews, it would be better to provide the participants with a printed copy of the interview questions before the time, to prepare themselves. This would help the language differences. 


\section{Conclusion}

Despite the UNESCO's (2014) report and Van der Berg et al.'s Grade R study both of which found that the poor quality of Grade $\mathrm{R}$ education may be because of the lack of parental support, the findings of the HSPP research project provided evidence that the programme increased parent's self-esteem, motivation and literacy skills. They were more able to participate in literacy skills and debates with their children in the home environment. They became mindful of the necessity that their children needed better opportunities that reflected their own culture and values to speak, read and write in English so they could compete in the larger more competitive society.

The parents involved in this study had been early school leavers and marginalised. They had been taught not to question but to accept and this limited their creative powers. They were now passionate about bringing change into their families, helping their children avoid the failure which they had experienced. The HSPP showed the parents that they could be liberated by asking questions and being critical in an anxiety-free environment. They learnt to plan their lives, read to their children with expression, made books, puzzles, played games, sang, danced and explored while listening and speaking. The HSPP, though small, is one way of ameliorating some of the inherited damage from the past and bringing about change in a practical, practio affordable manner. They now have a sense of directi want a better life.

\section{Acknowledgements Competing interests}

The authors declare that they have $n$ relationships which may have inapp them in writing this article.

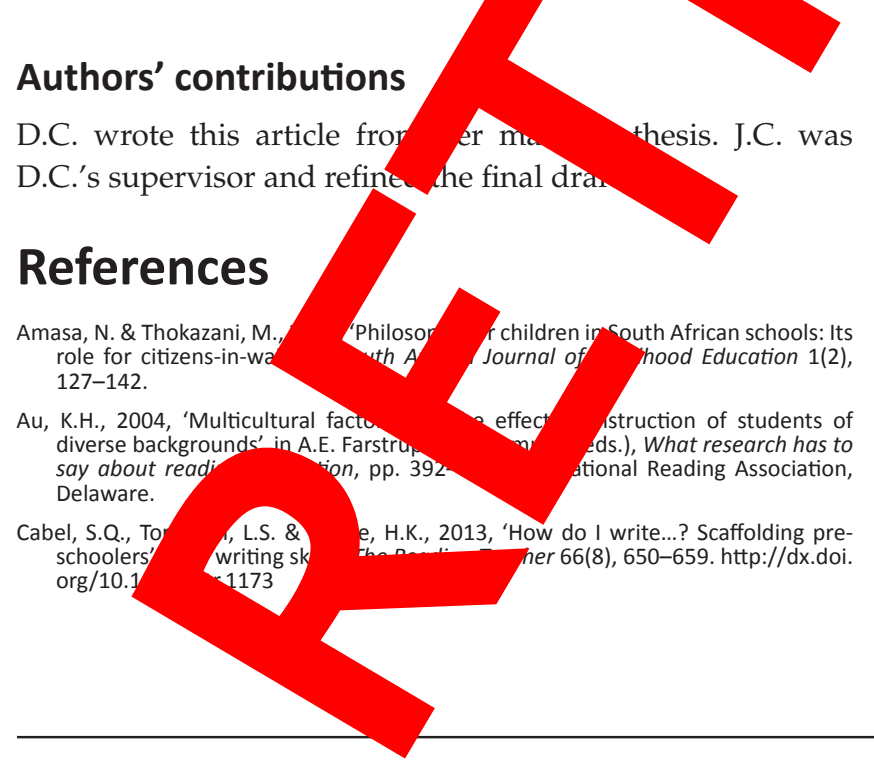

Chohan, S.K., 2011, 'Any letter for me? Relationships between an elementary school letter writing program and student attitudes, literacy achievement, and friendship culture', Early Childhood Education 39, 39-50. http://dx.doi.org/10.1007/s10643culture', Early

Cohen, L., Manion, L. \& Morrison, K., 2008, Research methods in education, 6th edn., Routledge, London.

Comrie, B., 2009, 'Home school par Supporting informal learning at home in the early yea wed 12 2014, from http://www. wordworks.org.za

Creswell, J.W., 2009, Resear approaches, 3rd edn., Sa

de Coulon, A., Meschi, E. \& Vir and non-cognitive $O$

Donald, D., Lazarus

Lolwana, P., 2007, Educan sychology in social context, reire, P., 1970,

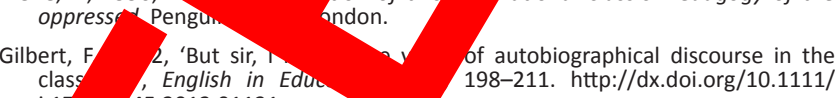
j.1 $345.2012 .01131 . x$

Girar Jametto, L., Weitzman, E. \& Greenberg, J., 2013, 'Educators' literacy

o emergent literacy contexts', Journal of Research in Childhood cation. http://dx.doi.org/10.1080/02568543.2012.739591 x, H.A., 2011, nedagogy, Continuum International, New York.

Goldstein, H., 2011, 'Know at to teach provides a roadmap for early literacy intervention', Journal fo Early Intervention 33(4), 268-280. http://dx.doi. org $/ 10.1177 / 1053815111429464$

Grisham-Brown, J., 2008, Fostering development milestones in your child. Early childhood development, viewed 8 February 2013, from http://www.education. com/reference rly-childhood-development

Henning, E., Van burg, W. \& Smit, B., 2007, Finding your way in qualitative research, Van ik, Pretoria.

arroll, S., 2013, Narrowing the gap: Making a case for the early language and literacy development in South Africa, viewed 15 om http://pediatrics.aappublications.org/content/129/1/e204

James, W., 2001, Manifesto on values, education and democracy, Government Printers, Pretoria.

hderson, J., 2008, 'At home with the Johars: Another look at family literacy', ading Teacher 62(3), 234-243. http://dx.doi.org/10.1598/RT.62.3.5

Neumann, M.M., Hood, M. \& Neumann, D.L., 2008, 'The scaffolding of emergent literacy skills in the home environment: A case study', Early Childhood Education 36, 313-319. http://dx.doi.org/10.1007/s10643-008-0291-y

'Carroll, S. n.d., WordWorks: changing lives through literacy, viewed 13 June 2015, from http://www.wordworks.org.za

O'Carroll, S., 2014, The home school partnership programme, viewed 13 June 2015 , from http://www.educationinnovations.org

Otto, B., 2008, Literacy development in early childhood, Pearson, New Jersey.

Shor, I., 1999, 'What is critical literacy?' in I. Shor \& C. Pari (eds.), Critical literacy in action: Writing words, changing worlds, pp. 1-30, Heinemann, Portsmouth.

Sotuku, N. \& Duku, N.S., 2014, 'Indigenous African theories in multicultural education', in C. Okeke, M. van Wyk \& N. Pasha (eds.), Schooling, society and inclusive education, pp. 17-38, Oxford University Press, Cape Town.

South Africa, 1996, Constitution of the Republic of South Africa act 10, viewed 12 February 2014, from http://www.gov.za/documents/constitution/1996/ constitution.pdf

South Africa, National Department of Education, 2002, Revised National curriculum statement. Grade R to 9. Policy document, Government Printer, Pretoria.

Swick, K.J., 2008, 'Empowering the parent-child relationship in homeless and other high-risk parents and families', Early Childhood Education Journals 36, 149-153. http://dx.doi.org/10.1007/s10643-007-0228-x

UNESCO, 2014, EFA global monitoring report. Teaching and learning: Achieving quality for all, UNESCO, Paris.

Van der Berg, S., Girdwood, E., Shepherd, D., Van Wyk, C., Kruger, J., Viljoen, J., et al., 2013, 'The impact of the introduction of Grade R on learning outcomes: Policy summary, executive summary \& evaluation report', University of Stellenbosch, Stellenbosch.

Zeece, P.D. \& Wallace, B.M., 2009, 'Books and good stuff: A strategy for building schoo and home literacy connections', Early Childhood Education 37, 35. http://dx.doi org/10.1007/s10643-009-0325-0 


\section{Appendix 1}

The HSPP seven-week literacy programme includes focusing on:

- parents as their children's first teacher;

- language learning and how young children learn best;

- drawing and have-a-go writing;
- strategies to support early reading and writing, including listening games;

- developing children's big and small muscles and knowledge of body in space;

- early maths using th

- summing up the $\mathrm{p}$ amme, cert. sand celebrations.

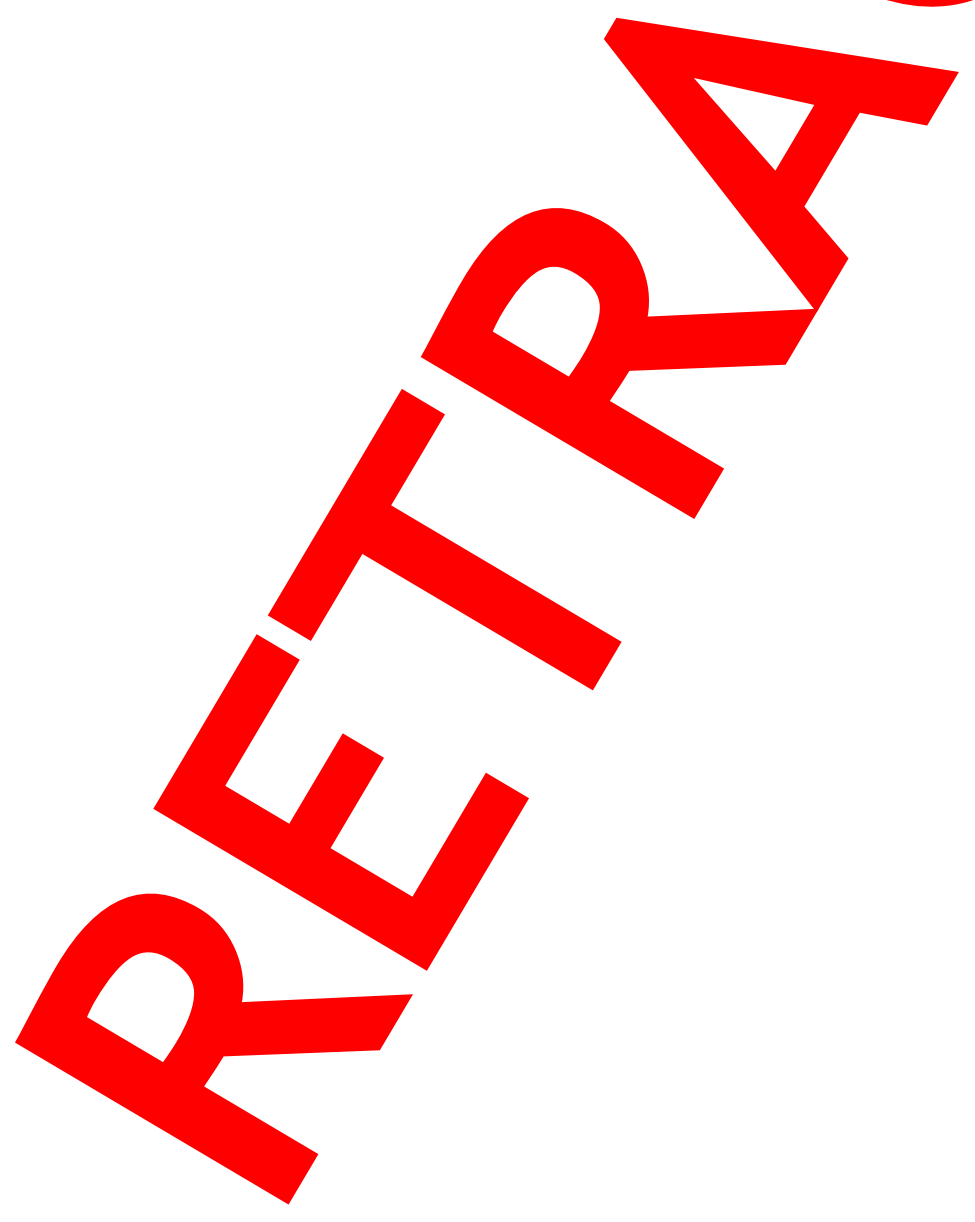

